\title{
THE Right TO LiBERTY IN A PANDEMIC
}

\author{
REBEKAH MCWHIRTER*
}

\begin{abstract}
The European Convention on Human Rights has given rise to the most extensive and influential case law of any human rights jurisdiction, and the inclusion of an express infectious diseases exception to the right to liberty suggests that its jurisprudence is likely to provide the best available guidance to states on the circumstances in which such measures may be justifiable and lawful. However, this article argues that the principles developed to date are limited in their applicability to the current crisis, and are insufficient for determining the appropriate balance between public health and the right to liberty when seeking to control the spread of a large-scale, highly infectious disease.
\end{abstract}

\section{INTRODUCTION}

Governments have struggled to respond effectively as the coronavirus pandemic has swept across the globe. In many places, various limitations on movement have been imposed in an effort to control the spread of severe acute respiratory syndrome coronavirus 2 (SARS-CoV-2), which causes coronavirus disease 2019 (COVID-19). Such measures have given rise to a range of responses from the public, from vehement support to outraged opposition..$^{1}$ Frequently, opposition is framed in terms of violation of human rights. States confronted with the task of responding to the pandemic are having to make rapid decisions on the basis of incomplete or uncertain information, balancing the competing imperatives of multiple fundamental human rights. Such decisions are particularly vulnerable to challenge on the basis of whether the appropriate balance has been struck.

For example, in the recent Victorian case of Loielo $v$ Giles ('Loielo'), ${ }^{2}$ Loielo contended that the nightly Melbourne curfew, imposed as part of a package of

\footnotetext{
Senior Lecturer in Health Law and Ethics, School of Medicine, Deakin University; Senior Research Fellow, School of Law, University of Tasmania. My thanks to Jenny Kaldor, Ryan Goss and attendees at the Australasian Association of Bioethics and Health Law Workshop 'Looking Forward/Looking Back: Law, Ethics and Policy in the Age of COVID-19' (online, 3-4 December 2020) for their helpful comments on an earlier draft of this article, as well as the editors and two anonymous referees for their helpful suggestions.

See, eg, the polarization of debate in Victoria into distinct camps: ' "Dictator Dan Mob" Versus the "I stand with Dan Crowd" Reflect Partisan Division' SkyNews (online, 17 September 2020) <https://www.skynews.com.au/details/_6191508290001>. For an international perspective, see Adam Chilton, Kevin Cope, Charles Crabtree and Mila Versteeg, 'Support for Restricting Liberty for Safety: Evidence During the Covid-19 Pandemic from the United States, Japan, and Israel' (SSRN preprint, 2 May 2020) <https://papers.ssrn.com/sol3/papers.cfm?abstract_id=3591270>. (2020) 63 VR 1 ('Loielo').
} 
interventions to reduce movement and prevent the spread of coronavirus, unlawfully infringed her rights to liberty and freedom of movement. In finding that the restrictions on human rights caused by the curfew were proportionate to the purpose of protecting public health, Ginnane J looked to the medical evidence on which the decision was made, the temporary duration of the measure, the purpose of the emergency powers, and the lack of other reasonably available means for achieving the same purpose. ${ }^{3}$ This case is, however, limited in what it can tell us about the lawfulness of restrictions on liberty for the purpose of protecting public health more generally, given its narrow focus on the nightly curfew rather than the full package of Victorian Stay at Home Directions that comprised one of the most severe (and successful) lockdowns in the world. ${ }^{4}$

Australia's international human rights obligations in this regard arise under the International Covenant on Civil and Political Rights, particularly art 12, which protects the right to liberty of movement while allowing for restrictions:

which are provided by law, are necessary to protect national security, public order (ordre public), public health or morals or the rights and freedoms of others, and are consistent with the other rights recognized in the present Covenant. 5

However, there is a dearth of case law from the Human Rights Committee addressing when the public health exception may be invoked or providing guidance on what the Covenant requires, limiting the extent to which it can inform domestic decision-making. The Loielo decision, and other cases examining compliance with Australian human rights Acts, ${ }^{6}$ frequently draw on the case law of the European Court of Human Rights ('the Court') as a potential source for persuasive authority, as a highly influential human rights jurisdiction. ${ }^{7}$ In this context, it is useful to consider the extent to which the Court's case law provides sufficient guidance to states on how to protect individual liberty in a pandemic.

In the aftermath of the 1918 Spanish flu pandemic, the drafters of the European Convention on Human Rights ('ECHR') had good reasons for including a public health exception to the right to liberty, and for expecting it to be widely

\footnotetext{
Ibid 11 [21].

Ibid 5-6 [1]; Deputy Public Health Commander (Vic), Stay at Home Directions (Restricted Areas) (No 15) (13 September 2020).

International Covenant on Civil and Political Rights, opened for signature 16 December 1966, 999 UNTS 171 (entered into force 23 March 1976) ('ICCPR').

Consideration of international law and the judgments of foreign and international courts and tribunals is provided for within Australian human rights acts; see, eg, Human Rights Act 2004 (ACT) s 31(1); Charter of Human Rights and Responsibilities 2006 (Vic) S 32(2); Human Rights Act 2019 (Qld) s 48(3).

The Court's case law has also been influential in Australian case law. See, eg, Michael Kirby, 'Australia and the European Court of Human Rights' (Conference Paper, Re-Appraising the Judicial Role - European and Australian Comparative Perspectives, 14 February 2011).
} 
utilised. ${ }^{8}$ Restrictions on personal liberty designed to address the current COVID19 pandemic engage the exception under art 5(1)(e), which provides that 'the lawful detention of persons for the prevention of the spreading of infectious diseases, of persons of unsound mind, alcoholics or drug addicts or vagrants' will not constitute a violation of the right to liberty and security.

While infectious diseases take precedence in this list, detention on the basis of mental health concerns has dominated the Court's case law on art 5(1)(e). Only one judgment addresses the infectious diseases exception, a case involving an HIV-positive man. ${ }^{9}$ HIV differs, in important respects, from those diseases likely envisaged by this exception. By contrast, the coronavirus underpinning the current pandemic would have fitted neatly within the drafters' expectations. Yet, states confronted with the task of responding to the pandemic have only case authority on HIV and mental health to guide their choice of interventions and ensure they comply with their obligation to protect the right to liberty.

This article argues that existing case law on art 5 of the ECHR provides insufficient guidance to states on how to protect individual liberty in a pandemic. It does this by, first, defining the key interventions used by states around the world to limit the spread of infection through physical separation of individuals, and considering whether they constitute deprivations or mere restrictions of liberty under the ECHR. Secondly, it examines the case law relating to the lawfulness, necessity and proportionality of measures taken under the infectious disease exception. From this analysis, three major limitations are identified. Finally, originalist and evolutive interpretations are compared to provide indications of future directions for art 5 jurisprudence.

\section{DEFINITIONS AND DEPRIVATIONS}

\section{A Typology of Interventions}

While waiting for an effective and safe vaccine to be developed and rolled out, a substantial part of state responses to the coronavirus pandemic involved variations on physical separation of individuals. The three most common forms employed by states were: ${ }^{10}$

\footnotetext{
Convention for the Protection of Human Rights and Fundamental Freedoms, opened for signature 4 November 1950, 213 UNTS 221 (entered into force 3 September 1953).

Enhorn v Sweden (ECtHR, Second Section, Application No 56529/00, 25 January 2005) ('Enhorn'). World Health Organisation, 'Considerations for implementing and adjusting public health and social measures in the context of COVID-19' (Web Page, 14 June 2021) < https://www.who.int/ publications/i/item/considerations-in-adjusting-public-health-and-social-measures-in-thecontext-of-covid-19-interim-guidances.
} 
1. 'Isolation', defined as the separation of ill persons from others so as to prevent the spread of infection;

2. 'Quarantine', defined as the separation from others of persons who are not known to be ill, but who may have been exposed to infection and may therefore be in the incubation phase of the disease, in order to prevent the possible spread of infection; and

3. 'Lockdown', defined as the imposition of restrictions on movement on persons within a defined geographical area, irrespective of individual risk of exposure, to the extent that individuals are predominantly confined to their place of residence, and may only leave for approved purposes and times, in order to restrict community transmission. ${ }^{11}$

Each of these measures differs in significant ways from the others. Isolation is directed at relatively small numbers of people, who present a high risk of transmission, but fails to capture those who are undiagnosed or asymptomatic but infectious. Quarantine affects a moderate number of people, who present a moderate risk of transmission as not all will be infectious, but excludes those not identified as having been at increased risk of exposure. Finally, lockdown affects large numbers of people, who individually pose a low risk of transmission, but reduces the opportunities for community transmission to the lowest feasible levels. The duration of these interventions can vary widely: patients may be discharged from isolation ten days after onset of symptoms plus at least three additional days without symptoms; ${ }^{12}$ quarantine is usually 14 days; ${ }^{13}$ and lockdowns can last from days to months. ${ }^{14}$

These terms are not used with consistent meaning in public discourse, and are frequently used interchangeably. For the purposes of this article, these terms have been defined to be consistent (as far as possible) with definitions under the World Health Organisation, International Health Regulations ( $3^{\text {rd }} \mathrm{ed}$, 2005) pt I, art 1 . Further, while recognising that lockdown, in particular, frequently involves additional measures, such as the closing of non-essential businesses and social distancing or mask requirements, the definition used here focuses on the aspects most relevant to an analysis of deprivation of liberty.

12 This equates to a minimum of ten days for asymptomatic patients, through to an indeterminate maximum depending on the number of symptomatic days. See World Health Organisation, 'Criteria for Releasing COVID-19 Patients from Isolation: Scientific Brief' (Web Page, 17 June 2020) <https://www.who.int/newsroom/commentaries/detail/criteria-for-releasing-covid-19-patients-from-isolation\#: : text=It\%20is \%20important\%20to\%20note,days\%20since\%20symptom\%20onset>.

13 World Health Organisation, 'Consideration for Quarantine of Contacts of COVID-19 Cases: Interim Guidance' (Web Page, 19 August 2020) <https://www.who.int/publications/i/item/considerations -for-quarantine-of-individuals-in-the-context-of-containment-for-coronavirus-disease(covid-19)>.

$14 \quad$ For example, South Australia imposed a six-day lockdown in November 2020 under the Emergency Management (Stay at Home No 3) (COVID-19) Directions 2020 pursuant to the Emergency Management Act 2004 (SA) s 25, and Victoria imposed a lockdown stretching for 112 days (nearly four months) from 7 July 2020 under a series of Stay at Home Directions (Restricted Areas) issued under the Public Health and Wellbeing Act 2008 (Vic) s 200. 
Despite these differences, in practice it is not always a straightforward exercise to distinguish between these interventions. For example, in early July 2020, the Deputy Chief Health Officer of Victoria issued directions under the Public Health and Wellbeing Act 2008 (Vic) detaining residents of nine Melbourne public housing towers to their homes. ${ }^{15}$ This intervention, which affected large numbers of people, was applied somewhat indiscriminately, and included very few approved reasons for leaving detention for any period of time, was popularly referred to as a lockdown. However, the directions were issued in response to an outbreak of COVID-19 associated with the North Melbourne public housing estate; that is, there was good reason to be believe that residents had been exposed to infection, and their detention was for the purpose of preventing the possible spread of infection..$^{16}$ On this basis, the intervention is best classified as a quarantine, rather than a lockdown. This approach is further supported by subsequent developments, in which restrictions on eight of the nine towers were eased following extensive testing for SARS-CoV-2, with restrictions remaining on one tower where more than 10 per cent of residents had returned positive test results. ${ }^{17}$ The unusually large scale of these interventions and the interchangeable use of terms in popular discourse perhaps obscure their classification, but being clear about the nature and purpose of an intervention is critical to determining whether any human rights infringements caused by it are justifiable, and conceptual clarity is therefore essential.

\section{B Deprivation or Mere Restriction?}

Isolation and quarantine appear prima facie to be clear examples of deprivations of liberty, in that the physical liberty of an individual is infringed through confinement (usually to a room or dwelling) for a non-trivial period of time. ${ }^{18}$ Lockdown, on the other hand, is less clear cut. Article 5(1) prohibits deprivation of liberty, in the sense of physical liberty of the person, and its purpose 'is to ensure that no one should be dispossessed of this liberty in an arbitrary fashion. ${ }^{19}$ To come within the scope of this article, the impugned conduct needs to exceed

15 Victorian Ombudsman, 'Investigation into the Detention and Treatment of Public Housing Residents Arising from a COVID-19 'Hard Lockdown' in July 2020' (Report, December 2020) 22. Ibid 49.

Ibid 12.

See, eg, UN GA Human Rights Council, Report of the Working Group on Arbitrary Detention, UN Doc A/HRC/45/16 (24 July 2020), annex II 35 [8].

Engel $v$ The Netherlands (1976) 22 Eur Court HR (ser A) 21 [58] ('Engel'). 
mere restriction of movement, which would fall under art 2 of Protocol No $4 \cdot^{20}$ However, there is no bright line between the two; the Court has described the difference as 'merely one of degree or intensity, and not one of nature or substance. ${ }^{21}$ Further, in determining whether an individual has been deprived of their liberty for the purposes of art 5, 'the starting point must be his concrete situation and account must be taken of a whole range of criteria such as the type, duration, effects and manner of implementation of the measure in question' ${ }^{22}$

Context can be influential. For example, in Engel $v$ The Netherlands ('Engel'), the Court considered whether different penalties imposed on soldiers in the Netherlands army for offences against military discipline constituted deprivations of liberty. ${ }^{23}$ The Court noted that, in being disciplined by confinement to their barracks for the lighter forms of discipline, the servicemen 'remain[ed], more or less, within the ordinary framework of their army life', ${ }^{24}$ and thus did not find them to have been deprived of their liberty. In doing so, the Court acknowledged that some restrictions on liberty are to be expected within the military context.

By contrast, in Guzzardi v Italy ('Guzzardi'), the Court found a violation of the right to liberty in circumstances involving comparatively greater freedom than the servicemen in Engel, by holding that if individual circumstances did not establish a deprivation of liberty, they could be considered 'cumulatively and in combination' to meet the requisite threshold. ${ }^{25}$ In this case, Guzzardi was placed under an order for special supervision and compulsory residence, requiring him to live on the island of Asinara. He was free to move about the island during the day, including visiting the town of Cala Reale, although he was confined to his residence between $10 \mathrm{pm}$ and $7 \mathrm{am}$ each night and was required to report to authorities twice a day. In making its finding, the Court emphasised the limited area within which Guzzardi could move, the dilapidated state of the lodgings, and the limited opportunities for social contacts, combined with the extended period

$20 \quad$ Ibid 21 [57]; De Tommaso v Italy (European Court of Human Rights, Grand Chamber, Application No 43395/09, 23 February 2017) 20 [80] ('De Tommaso'); Protocol No 4 to the Convention for the Protection of Human Rights and Fundamental Freedoms, securing certain rights and freedoms other than those already included in the Convention and in the first Protocol thereto, opened for signature 16 September 1963, ETS No 46, as amended by Protocol No 11 to the Convention for the Protection of Human Rights and Fundamental Freedoms, opened for signature 11 May 1994, ETS No 155 (entered into force 1 November 1998) ('Protocol No 4').

21 Guzzardi v Italy (1980) 39 Eur Court HR (ser A) 30 [93] ('Guzzardi'). For application in Australia, see Re Kracke and Mental Health Review Board (2009) 29 VAR 1109 [664].

22 Guzzardi (n 21) 29-30 [92]. See also Engel (n 19) 21-2 [59]; Medvedyev v France (European Court of Human Rights, Grand Chamber, Application No 3394/03, 29 March 2010) 25 [73]; De Tommaso (n 20) $20[80]$.

23 Engel (n 19).

$24 \quad$ Ibid 22 [61].

25 Guzzardi (n 21) 30 [95]. 
of his residence. ${ }^{26}$ Given the extent of restrictions in lockdown, the degree of control over the movement of individuals, and the extent of social isolation experienced by individuals, a strong case could be made for lockdown representing a deprivation of liberty.

Whether a particular lockdown is found to be a deprivation of liberty will depend on the specific effects on the individual complainant, rather than the general effects of the lockdown on the population, as was made clear in the recent case of Terheş $v$ Romania. ${ }^{27}$ The Court found that Terheş had not explicitly detailed the effects of the 52-day Romanian lockdown on his life. ${ }^{28}$ In contrast to Guzzardi, the Court considered that Terheş had not been deprived of all social contact, was not forced to live in a cramped space, and was free to leave his home for specific reasons, and so his situation could not be equated with house arrest and therefore did not constitute a deprivation of liberty. ${ }^{29}$ This suggests that an individual affected more severely than Terheş, such as elderly people deprived of all social contact or casualised workers deprived of all income, might be able to establish a deprivation of liberty under lockdown, although precisely where that threshold lies is currently unclear.

In Loielo, Ginnane $\mathrm{J}$ found that the curfew direction engaged the right to freedom of movement, but not the right to liberty. ${ }^{30}$ In reaching this conclusion, Ginnane J drew on Convention-related decisions that found 'that not all measures confining a person to their home are deprivations of liberty.' ${ }^{31}$ His Honour focused particularly on Secretary of State for the Home Department $v \mathrm{JJ}$, an English case applying the principles established by the Strasbourg Court in relation to the right to liberty, and the emphasis in that judgment on assessing the impact of the measure on the person affected, including 'the actual lives these people were required by law to lead, how far they were confined to one place, how much they were cut off from society, how closely their lives were controlled.' ${ }^{32}$ On this basis, Ginnane J held that the impact of the curfew on Loielo's life was such that right to freedom of movement was engaged, but not the right to liberty. Significantly, Loielo's complaint related to the personal effect of the restrictions on her arising only from the curfew. This leaves open the possibility that the Victorian lockdown taken as a whole might constitute a restriction on the right to liberty, and that

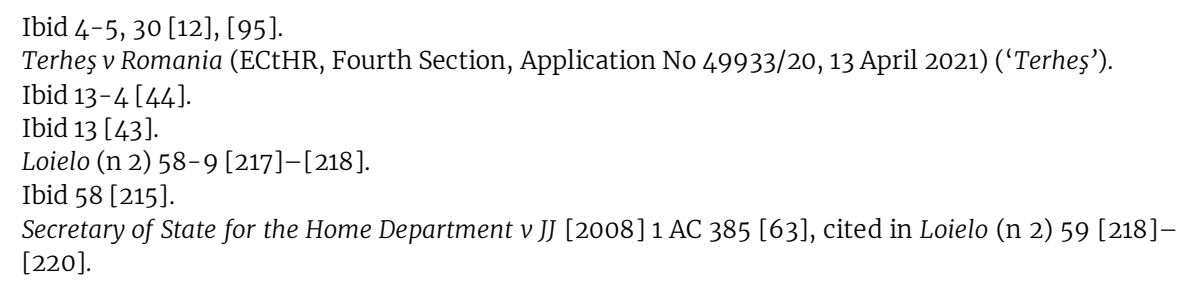


other people's experience of the curfew may, as a result of their particular circumstances, engage the right to liberty instead of freedom of movement. ${ }^{33}$

\section{In the Interests of the Common Good?}

In assessing the 'type' and 'manner of implementation' of a given measure, the Court may have regard to the context in which the action is taken. The Court in Austin $v$ the United Kingdom ('Austin') held context to be 'an important factor ... since situations commonly occur in modern society where the public may be called upon to endure restrictions on freedom of movement or liberty in the interests of the common good. ${ }^{3} 3$ The facts in Austin did not fall within one of the permissible grounds for deprivation of liberty listed under art 5(1), but the actions were held to be necessary 'to avert a real risk of serious injury or damage', and the Court noted that the actions used were 'the least intrusive and most effective means to be applied' ${ }^{35}$ This approach holds that art 5 prohibits only arbitrary deprivations of liberty, and appears to introduce a proportionality-style test into the definitional stage of an art 5 analysis. As Feldman has noted, allowing such considerations at the definitional stage potentially poses a problem for people in countries that have not signed onto Protocol No 4. ${ }^{36}$ This would leave them without a right to freedom of movement and, thus, 'without a legal remedy for any confinement if the detainor could persuade a court that there was a good, public interest reason for it, even if the reason lay outside the range of permitted justifications for depriving someone of liberty. ${ }^{37}$

On this approach, an argument could be made that lockdown is a restriction implemented in the interests of the common good, to prevent serious harm to the community. It is therefore arguably not an arbitrary deprivation of liberty and thus not within art 5 . This argument is unlikely to be advanced for two reasons. First, the existence of the infectious diseases exception under art 5(1)(e) renders it somewhat redundant. Second, it is inconsistent with other recent Grand Chamber judgments, which hold that the purpose behind restrictions 'no longer appears decisive for the Court's assessment of whether there has in fact been a

This latter possibility was expressly acknowledged, and the former possibility hinted at, by Ginnane J: Loielo (n 2) 5-6 [1], 60 [222].

34 Austin $v$ the United Kingdom (European Court of Human Rights, Grand Chamber, Application Nos 39692/09, 40713/09 and 41008/09, 15 March 2012) 23 [59].

Ibid 23-4 [66].

Protocol No 4 (n 20).

David Feldman, 'Counter-Infection Methods and ECHR Article 5' (2020) 25(2) Judicial Review 80, 86. 
deprivation of liberty' and that purpose is taken 'into account only at a later stage of its analysis', casting doubt on its continued relevance. ${ }^{38}$

However, in Terhess, the Court seemed to take the purpose of the lockdown into consideration when evaluating whether it represented a deprivation of the right to liberty, noting that if the authorities had not taken such extreme measures, there would have been serious consequences for the rights to life and health. ${ }^{39}$ While this may have been merely a contextual observation, given the extent of the restrictions under consideration, it suggests that the purpose of prevention of serious harm to the community was influential in the Court's reasoning here, in spite of the availability of an infectious diseases exception.

\section{The Infectious Diseases EXCEPTION}

\section{A Lawfulness}

Assuming all three interventions constitute a deprivation of liberty, they might nevertheless be lawful if they are found to fall within the grounds in art 5(1)(e). Lawfulness requires compliance with 'a procedure prescribed by law'. This domestic law must itself comply with the general principles implied in art 5 of the ECHR: the rule of law (including legal certainty); proportionality; and protection against arbitrariness, which is 'the very aim' of art 5 and runs throughout all elements of art 5 analyses. $4^{0}$

Legal certainty is a challenge for domestic legislators: laws have been implemented rapidly, in evolving circumstances and with limited reliable clinical information, contributing to difficulties in creating accessible, precise and foreseeable laws. Provisions for isolation and quarantine are relatively easy to articulate, remain reasonably stable over time, and draw on past practice. By contrast, lockdown is comparatively novel. It is difficult to specify the duration of lockdown, undermining the goal of precise and foreseeable laws. Hastily enacted legislation has also resulted in ambiguities. For example, the legality of English and Welsh Regulations issued under the Public Health (Control of Diseases) Act 1984 (UK) to authorise lockdowns has been called into question. Hickman and colleagues argued that there is 'a significant question mark' over whether the Act

Creangă v Romania (European Court of Human Rights, Grand Chamber, Application No 29226/03, 23 February 2012) 31-2 [93]; Rozhkov v Russia (No 2) (European Court of Human Rights, Third Section, Application No 38898/04, 31 January 2017) 13 [74]. See also Merabishvili $v$ Georgia (European Court of Human Rights, Grand Chamber, Application No 72508/13, 28 November 2017) 71 [298]. Terheş (n 27) 12-3 [40]. Simons v Belgium (ECtHR, Second Section, Application No 71407/10, 28 August 2012) 9-10 [32]. 
authorises restrictions on the movement of the general population, ${ }^{41}$ while King has argued that it is 'reasonably clear' that the Act 'can be construed literally to confer powers to impose the lockdown.' ${ }^{42}$ Either way, as Blair observed, 'if there is a question mark over the vires of the subsidiary legislation creating these restrictions, it would surely be preferable for the powers to be explicitly authorised by Parliament.' 43

Emergency circumstances can create conditions that hamper compliance in the application of existing laws. The use of emergency detention powers on the Melbourne public housing towers was undertaken at such speed that there was insufficient time for the human rights implications of the intervention to be properly considered, as required. This resulted in inadequate planning and preparation and, in turn, additional - and avoidable - human rights breaches caused by deficiencies in implementation. 44

Further, the rapid introduction of lockdown laws has led to a lack of precision and broad discretion in enforcement, which arguably introduces an element of arbitrariness. For example, lockdown in Spain was enforced under the Organic Law on Citizens' Security (Law no 4/2015), which has a history of arbitrary application, and the Spanish Ombudsman is investigating whether fines have been issued correctly and proportionately. ${ }^{45}$ In the United Kingdom, confusion between regulations and non-binding health advice may have contributed to excessive use of discretionary powers by police. ${ }^{46}$ And in New Zealand, stay-at-home instructions issued by the government went beyond the health order made by the Director-General of Health, with the result that the first nine days of lockdown had no legal basis. ${ }^{47}$ This was rectified through a second health order being issued, but highlights the ease with which mistakes of this nature can be made when responding to a rapidly evolving crisis..$^{48}$

Importantly, however, Convention case law in this area is clear. While practical challenges are undeniable, legislators know the standard required: the

\footnotetext{
Tom Hickman, Emma Dixon and Rachel Jones, 'Coronavirus and Civil Liberties in the UK', Blackstone Chambers (Article, 6 April 2020) 10 [340] <https://coronavirus.blackstonechambers. com/coronavirus-and-civil-liberties-uk/>.

Jeff King, 'The Lockdown is Lawful', UK Constitutional Law Blog (Blog Post, 1 April 2020) <https://ukconstitutionallaw.org/2020/04/01/jeff-king-the-lockdown-is-lawful/>.

David Blair, 'Human Rights' (2020) 65(5) Journal of the Law Society of Scotland 31.

Victorian Ombudsman (n 15) 14; 18.

Fran Warren, Francesca Gualco, Hannah Davidson and Ella Edginton, Part 1 - International Policing Responses to COVID-19: During Lockdown (Research Report, Scottish Government, 27 July 2020) $<$ https://www.gov.scot/publications/part-1-international-policing-responses-covid-19during-lockdown/pages/17/>.

Liora Lazarus, 'Introduction' in Bonavero Institute of Human Rights, A Preliminary Human Rights Assessment of Legislative and Regulatory Responses to the COVID-19 Pandemic across 11 Jurisdictions (Bonavero Report No 3/2020, 6 May 2020) 13.

Borrowdale v Director-General of Health [2020] NZHC 2090.

Director-General of Health (NZ), Section 7o(1)(f) Health Act Order (3 April 2020).
} 
law must outline the conditions for deprivation of liberty sufficiently clearly and precisely 'to allow the person - if need be, with appropriate advice - to foresee, to a degree that is reasonable in the circumstances, the consequences which a given action may entail'.49 Relevant elements, or 'safeguards against arbitrariness', include 'the existence of clear legal provisions for ordering detention, for extending detention, and for setting time-limits for detention', as well as a mechanism for contesting the lawfulness and length of detention.50 Despite the practical challenges, the guidance provided by the Court on this aspect is sufficient to allow states to work towards meeting the requisite standard, even if their initial efforts fall short. The same cannot be said of the requirements of necessity and proportionality.

\section{B Necessity and Proportionality}

All three interventions are clearly intended to pursue the legitimate aim, with respect to COVID-19, of 'the prevention of the spreading of infectious diseases', found in art 5(1)(e). In assessing whether they are also necessary and proportionate means for doing so, there is only one ECHR case to draw upon. In Enhorn $v$ Sweden ('Enhorn'), the Court was asked to consider whether the compulsory isolation of an HIV-positive man constituted a violation of art 5(1) of the ECHR ${ }^{51}$ Enhorn had unknowingly transmitted HIV to another man prior to his diagnosis, and was given instructions by the county medical officer aimed at preventing further transmission. After failing to keep several medical appointments, the Administrative Court found he had failed to comply with the prescribed measures and ordered compulsory detention at the hospital for up to three months. This was repeatedly renewed every six months, although Enhorn absconded for prolonged periods. The parties agreed that the isolation orders amounted to a deprivation of liberty, and that the purpose of Enhorn's detention was to prevent him from infecting others with HIV. As such, the order could be examined under art 5(1)(e).52

In an example of understatement, the Court observed that it had 'only to a very limited extent decided cases where a person has been detained "for the prevention of the spreading of infectious diseases"' and was for that reason 'called upon to establish which criteria are relevant when assessing whether such a detention is in compliance with the principle of proportionality and the requirement that any detention must be free from arbitrariness. ${ }^{53}$ The Court drew

\footnotetext{
Khlaifia $v$ Italy (ECtHR, Grand Chamber, Application No 16483/12, 15 December 2016) 38 [92]. JN $v$ United Kingdom (ECtHR, First Section, Application No 37289/12, 19 May 2016) 19-20 [77]. Enhorn (n 9). Ibid 15-16 [33]-[35]. Ibid 18 [41].
} 
on the comparatively voluminous case law relating to the detention of persons 'of unsound mind'. In particular, the judgment highlighted the Winterwerp criteria, drawn from Winterwerp $v$ the Netherlands, 54 which comprise the minimum conditions for justification of detention on mental health grounds:

firstly, he must reliably be shown to be of unsound mind; secondly, the mental disorder must be of a kind or degree warranting compulsory confinement; and thirdly, the validity of continued confinement depends upon the persistence of such a disorder. 55

To these was added the requirement that 'there must be some relationship between the ground of permitted deprivation of liberty relied on and the place and conditions of detention', ${ }^{56}$ citing Ashingdane $v$ the United Kingdom as authority for the principle that lawful detention of a mental health patient can only be effected in a hospital, clinic or similarly appropriate institution. ${ }^{57}$

The Court drew an explicit link between each of the categories of person listed in art 5(1)(e), reasoning that all of the listed conditions justified detention of individuals posing a threat to public safety, as well as in their own interests (for treatment or to prevent self-harm). This claim perhaps elides the very real difference in the purpose of deprivations of liberty of people with an infectious disease, which is predominantly for the protection of the public, and people with a mental illness, which must have a therapeutic purpose. ${ }^{58}$ Nevertheless, the Court adapted the Winterwerp criteria to the infectious disease context, articulating the 'essential criteria' to be:

whether the spreading of the infectious disease is dangerous to public health or safety, and whether detention of the person infected is the last resort in order to prevent the spreading of the disease, because less severe measures have been considered and found to be insufficient to safeguard the public interest. 59

These criteria speak directly to necessity (danger to public health or safety) and proportionality (least severe measure able to sufficiently safeguard the public interest), but are less informative regarding appropriate thresholds for 'danger' or 'sufficiency'. In the application of these criteria in Enhorn, the Court found HIV to be indisputably dangerous to public health and safety. ${ }^{60}$ Certainly, at the time of Enhorn's original isolation order in the mid-1990s, HIV was among the most feared of infectious diseases, but without any reasoning this finding adds little to

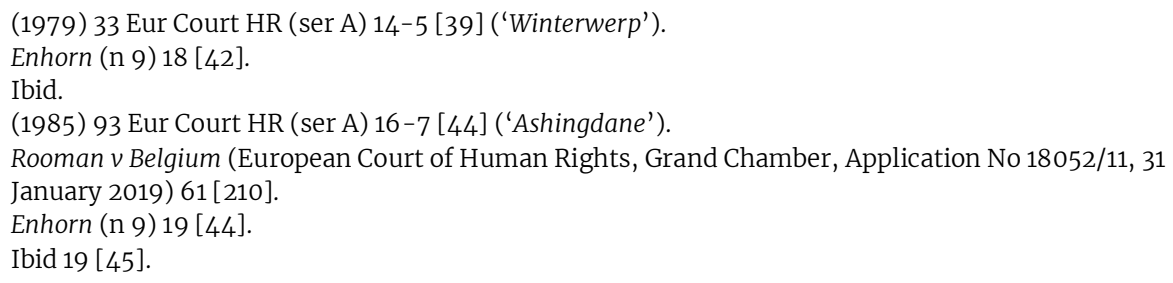


our understanding of what constitutes sufficient danger to the public to warrant detention.

It is notable that the Court framed the issue in terms of the danger of the virus, without consideration of mode of transmission, available treatments or other potentially mitigating factors, given that so much of the judgment was devoted to examining evidence of the risk posed by Enhorn to others. As HIV transmission requires contact with bodily fluids, risk of transmission would seem to be a relevant consideration in determining necessity of detention. Judge Costa addressed transmissibility in terms of intention, rather than risk, suggesting that detention was:

acceptable only for limited periods ('quarantine'), where the disease is curable, as in the case of tuberculosis (I do not think that placement in a sanatorium is in principle contrary to Article 5), and where the disease is spread unintentionally, which is not normally the case with sexually transmitted diseases ... ${ }^{61}$

There is no doubt that risk is a difficult concept to integrate into legal frameworks, as it is usually determined on the basis of incomplete information and, even when it is possible to calculate, does not tell us what is an acceptable risk. As Martin noted, in other fields, the 'precautionary principle' is applied when there is a risk of significant or irreversible harm, even in the absence of all the relevant information. ${ }^{62}$ Yet in relation to the right to liberty, the presumption is weighted in the other direction, as articulated in Enhorn:

detention of an individual is such a serious measure that it is only justified where other, less severe measures have been considered and found to be insufficient to safeguard the individual or the public interest which might require that the person concerned be detained. 63

Interestingly, in Loielo, Ginnane J noted that the Victorian Public Health and Wellbeing Act 2008 included a provision endorsing the precautionary principle. Section 6 provides that:

If a public health risk poses a serious threat, lack of full scientific certainty should not be used as a reason for postponing measures to prevent or control the public health risk.

In the context of the use of deprivation of liberty to control a threat to public health, this public health provision is potentially in tension with human rights case law to date. Evidence for the efficacy of the curfew as an independent factor in reducing SARS-CoV-2 infections was not strong, as its effect could not be disentangled from the wider package of interventions. As a result, it perhaps does

61 Ibid 25 [11] (concurring opinion of Judge Costa).

62 Robyn Martin, 'The Exercise of Public Health Powers in Cases of Infectious Disease: Human Rights Implications: Enhorn v Sweden' (2006) 14(1) Medical Law Review 132, 141.

63 Enhorn (n 9) 16 [36]. 
not align well with the presumption in favour of liberty, except that in this case, the focus was restricted to the curfew, and a lower threshold appears to be applied to considerations of freedom of movement compared to deprivation of liberty. Measures that constitute deprivations of liberty must be both effective in safeguarding the public interest and also the least severe option available to achieve that goal. It is not clear from Loielo how the precautionary principle in s 6 might interact with the need for any proposed measure to involve the 'minimum restriction on the rights of any person', ${ }^{64}$ in a proportionate and non-arbitrary manner, ${ }^{65}$ and ECHR case law provides no guidance.

The Court found that the second criterion, relating to necessity, had not been fulfilled in Enhorn, 'because less severe measures had not been considered and found to be insufficient to safeguard the public interest. ${ }^{166}$ Interestingly, the Court added a further consideration at this point, observing that - in extending the compulsory isolation order over almost seven years, including one and a half years of involuntary detention in a hospital - 'the authorities failed to strike a fair balance between the need to ensure that the HIV virus did not spread and the applicant's right to liberty.' ${ }^{67}$ In a concurring opinion, Judge Cabral Barreto distanced himself from this inclusion of balancing in the reasoning, stating:

[I]t follows both from the letter of the Court's settled case-law on deprivation of liberty and, above all, from the spirit that has imbued it and continues to do so, that if a review of a measure depriving a person of his liberty were to allow the State a certain margin of appreciation in such matters, this would not in any way accord with a line of case-law which ... has taken care to stress the importance of the Article 5 safeguards .$^{68}$

The problem with framing the evaluation in terms of 'balancing' is that the assumptions underpinning the weighting on each side of the scales are hidden. Here, it appears that the Court viewed the risk to Enhorn's liberty as of greater weight than the risk to the public. Presciently, in 2006 Martin warned:

The decision in Enhorn prioritised the private right of liberty over the public benefit of disease protection in a case of HIV/AIDS, despite the assessment of government public health officials that there was some risk to public health. The extent to which this decision can serve as a precedent where the risk is of large-scale, fast-spreading disease of unknown epidemiology is questionable ${ }^{69}$

\footnotetext{
Public Health and Wellbeing Act 2008 (Vic) s 111.

Ibid s 9.

Enhorn (n 9) 21 [55].

Ibid.

Ibid 28 (concurring opinion of Judge Cabral Barreto). Although the margin of appreciation is an important part of ECHR judgments, and it might be expected that a wide margin would be afforded to states managing a pandemic, Judge Cabral Barreto's comments here reflect the fact that the preponderance of case law is against the application of the margin of appreciation to art 5 . Martin (n 62) 142 (emphasis added).
} 
This warning was borne out in Loielo, in which the challenge of using a 'balancing' approach was identified in the legal advice relating to the compliance of the curfew with the Charter of Human Rights and Responsibilities 2006 (Vic):

[T] here is some risk of incompatibility with respect to the evening curfew. We draw your attention to the fact that the more onerous the limits become, the more difficult it is to assess whether the balance they strike is proportionate with their objective in part because it is not possible to consider how those limits will impact each individual. ${ }^{70}$

That is, the scale of the intervention raised issues in evaluating its impact. Enhorn and cases relating to detention on mental health grounds considered particular individuals, and emphasised that analysis should focus on the actual effects of the law on those individual lives. In stark contrast, lockdown measures affect large numbers of individuals, whose lives may be impacted in various ways and in varying degrees, complicating the human rights analysis in a way that means that the existing case law is of little assistance.

\section{LIMITATIONS}

Presented with a case involving an infectious disease of a particular type, the Court in Enhorn drew an analogy with mental illness that was adequate for the case at hand, but which reveals significant problems when applied to other infectious diseases. From the analysis above, three major limitations can be identified, relating to thresholds, risk and affected status of individuals.

\section{A Thresholds}

There is a lack of guidance on how to determine what constitutes sufficient danger to public health and safety or whether a given measure is sufficient to safeguard the public interest. Evidence about the long-term effects of COVID-19 is lacking, but it appears that in the majority of cases it can be a relatively mild disease. The threat comes from its highly infectious nature and the consequently large number of cases. This means that even if only a small proportion of cases result in death, the absolute figures will still be very large. Further, such large numbers threaten to overwhelm health systems, reducing the ability to effectively care for affected individuals as well as those in need of healthcare for other reasons.

This would seem sufficient to establish a clear danger to public health and safety. Yet some commentators have argued that lockdowns are fundamentally incompatible with the basic purpose of art 5, in that 'they reverse the essential 
principle of art 5 that liberty is the rule and deprivation of it must be strictly limited and rigorously justified. Instead, ... confinement is the rule, and leaving confinement requires a "reasonable excuse". ${ }^{71}$ Others, such as King, point out that the rights to life and health of others in society, as well as the rights of health service staff to just working conditions, are equally important. ${ }^{72}$ King further argues that there is 'basic compatibility between the lockdown and human rights principles' as long as it is 'lawful, non-discriminatory and strictly proportionate'..$^{73}$

It is in ensuring continued proportionality that governments are mostly likely to encounter difficulties. At what point during a lockdown is the threat to the public sufficiently diminished? At ten cases per day? Or five? Or none? Lazarus suggests that:

While extreme lockdown measures may well be justified in the initial short term, the State is required to seek out all alternative measures (such as upscaling medical health provision and testing) as the pandemic progresses. It cannot rely indefinitely on extreme measures alone. 74

This implies that continual re-evaluation of the necessity and relative effectiveness of lockdown will be important. Feldman goes further, and warns against the potential for 'long-term, widespread deprivation of people's liberty, accepted pragmatically in the face of a special threat' to become normalised and to erode the presumption of liberty as the default position. ${ }^{75} \mathrm{He}$ argues that such responses were historically not used for other infectious and potentially fatal diseases, and that 'requiring the population as a whole to sacrifice its liberty to protect potentially vulnerable people violates art 5 of the ECHR and tends to undermine the foundation of a liberal society. ${ }^{76} \mathrm{He}$ does, however, concede that it may be reasonable to facilitate the voluntary isolation of vulnerable people.

This approach appears to assume that vulnerable people constitute a small and identifiable minority. Emerging epidemiological evidence suggests that this may understate the extent of vulnerability to COVID-19, as well as the significant risks to the general public presented by overwhelmed health systems. Feldman's position fails to account for the impacts on the rights to life and health that would result in the absence of lockdown. Viewed in this way, arguments that lockdowns are intended to protect far more than a limited set of potentially vulnerable people seem more persuasive.

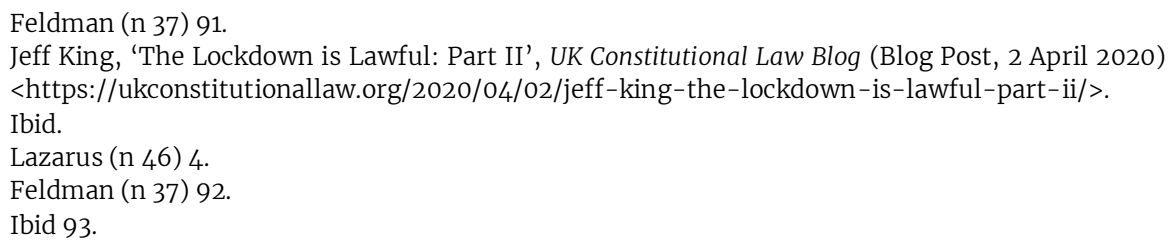


Nevertheless, restrictions on liberty need to be justified, reviewable and temporary. These requirements are echoed, for example, by the Working Group on Arbitrary Detention of the United Nations Human Rights Council, who note that even in a public health emergency, '[a]ll ... measures must be publicly declared, be strictly proportionate to the threat to the public caused by the emergency, be the least intrusive means to protect public health and be imposed only for the time required to combat the emergency.' 77 This imperative, however, does not address the central issue of how to identify when the tipping point has been reached and lockdown can no longer be justified, especially in circumstances of uncertainty or where any available less severe measures are likely to be comparatively less effective. Uncertainty may be especially acute in circumstances in which it is not clear that a vaccine or other alternative mechanism will be forthcoming, and transitioning to an endemic disease state may be appropriate, making it difficult to identify when the public health emergency is over.

\section{B Risk}

The failure to engage with the concept of risk ignores a fundamental element of public health decision-making, creating a disjuncture between municipal practice and human rights analysis. Perception and assessment of risk has been critical to all aspects of responding to the COVID-19 pandemic, with decisions resting on assessments of the risk of transmission, of serious illness or death, of health systems' inability to cope, of masks or social distancing not preventing transmission, and so on. In Loielo, it was clear that the decision to retain the curfew as part of the public health response was founded entirely on considerations of risk:

[I]t reduces movement, which in turn reduces the risk of community transmission. Further, it is one part of a suite of measures that have proven to be highly effective in reducing community transmission. There is a risk that removing the curfew component from this suite may undermine the effectiveness of the measures taken together; this risk is considered to be unacceptably high. ${ }^{78}$

This was, as Ginnane J observed, the 'cautious or precautionary approach', ${ }^{79}$ and it is somewhat at odds with cases such as Enhorn, in which the presumption in favour of liberty displaces consideration of the precautionary principle. This is likely to be a consequence of the focus within the case law to date on detention of individuals, rather than large groups of people, which has allowed the centrality

\footnotetext{
Human Rights Council (n 18) annex II 34 [3].

Loielo (n 2) 62 [230].

Ibid 68 [253].
} 
of risk to public health decision making to be understated. Risk is potentially relevant to establishing both the necessity and proportionality of a measure, but the current case law provides no guidance as to how information pertaining to risk should be used, how it should be balanced against the imperative to protect individual liberty, or the extent to which use of the precautionary principle is consistent with the right to liberty.

\section{Affected Status}

All art 5(1)(e) case law to date has focused on the detention of affected individuals. ${ }^{80}$ This facilitates an analysis of isolation measures, which only applies to diagnosed cases, but it is unclear how these principles should be applied to undiagnosed individuals, as in quarantine and lockdown. Greene argued that it is unlikely and undesirable that the infectious disease exception be expanded to include the ability to deprive healthy people of their liberty to prevent the spread of disease ${ }^{81}$ Hickman and colleagues were strongly critical of this approach, noting that there is nothing in the wording of art 5(1)(e) precluding its application to healthy persons; the focus on affected individuals, they suggest, is simply an artefact of the types of cases brought before the Court. ${ }^{82}$ Feldman agreed that the language of the exception was capable of supporting application to healthy people, but noted that establishing the necessity of detention of non-infectious individuals may be more difficult, and might potentially lead to issues of arbitrariness. ${ }^{83}$

This point was addressed in Loielo, where it was reasoned that the curfew direction was not depriving people of their liberty in an arbitrary manner because there were exceptions that addressed core needs of affected individuals, it was reasonably justified, and it was a temporary measure. ${ }^{84}$ The logical consequence of Greene's approach, however, is that the early lockdown of a relatively small area in order to prevent widespread infection would be prohibited, prioritising the right to liberty of a few individuals over the rights to life and health of potentially many more individuals. Reconciling the need to avoid arbitrariness with the need to prevent potentially greater future infringements of rights is likely to require a means of evaluating risk as part of the necessity and proportionality analyses.

\footnotetext{
See, eg, Enhorn (n 9); Winterwerp (n 54); Ashingdane (n 57).

Alan Greene, 'States Should Declare a State of Emergency using Article 15 ECHR to Confront the Coronavirus Pandemic', Strasbourg Observers (Blog Post, 1 April 2020) <https:// strasbourgobservers.com/2020/04/01/states-should-declare-a-state-of-emergency-usingarticle-15-echr-to-confront-the-coronavirus-pandemic/>.

Hickman, Dixon and Jones (n 41).

Feldman (n 37) 87.

Loielo (n 2) 63 [233].
} 


\section{THEORIES OF INTERPRETATION}

Greene has suggested that states should declare a State of Emergency under art 15 of the ECHR, so that derogations from art 5 in the form of public health interventions can be pursued without attracting the scrutiny of the Court. ${ }^{85}$ This, he argues, means that 'any jurisprudence of the ECtHR that may be affected by undue deference in a time of crisis can be quarantined to the exceptionality of the situation. ${ }^{86}$ This seems an unhelpful approach, given the complete lack of safeguards or interrogations of justifications for particular actions under art 15 derogations and the fact that - far from representing an exceptional outlier the present pandemic is very likely exactly the type of situation envisaged by the drafters of the ECHR when including the infectious disease exception.

This is not to suggest that an originalist interpretation is appropriate. Although an originalist approach may be appealing in its delegation of decisions to appointed legislators and consequent restraint of creativity by unelected judges, too great a focus on the origins of the ECHR would fail to appreciate the significant evolution in function and mission since its drafting. ${ }^{87}$ The Court has, since Tyrer $v$ United Kingdom, ${ }^{88}$ developed an evolutive approach to interpretation, which conceives of the ECHR as a 'living instrument' and which, as Letsas explained, 'puts the emphasis upon present-day conditions as an important factor in interpreting the Convention' ${ }^{89}$ Drafters' intentions are only relevant insofar as they advance or elucidate the object and purpose of the ECHR. ${ }^{\circ}$ The application of this approach to interpreting art 5 is evident in Judge Costa's concurring opinion in Enhorn:

Similarly, art 4(1) of the ICCPR (n 5) provides that States may derogate from their obligations under that Convention 'to the extent strictly required by the exigencies of the situation' in a 'time of public emergency which threatens the life of the nation and the existence of which is officially proclaimed'. Note, however, that the United Nations Human Rights Committee issued guidance on the use of emergency measures in relation to COVID-19 and recommended that 'measures suspending rights should be avoided when the situation can be adequately dealt with by establishing proportionate restrictions or limitations on certain rights': United Nations Human Rights Office of the High Commissioner, 'Emergency Measures and COVID-19: Guidance' (Newsletter, 27 April 2020) <https://www.ohchr.org/Documents/Events/EmergencyMeasures_ COVID19.pdf>. Greene (n 81).

87 A trap arguably exemplified by Sir Gerald Fitzmaurice's dissent-filled tenure on the Strasbourg Court. See, eg, his dissenting opinion in Marckx v Belgium (1979) 31 Eur Court HR (ser A). See also Ed Bates, The Evolution of the European Convention on Human Rights (Oxford University Press, 2010) $361-5$. Tyrer v United Kingdom (1978) 26 Eur Court HR (ser A) 11-2 [30].

89 George Letsas, A Theory of Interpretation of the European Convention on Human Rights (Oxford University Press, 2018) 76.

$90 \quad$ Ibid 72; see also Vienna Convention on the Law of Treaties, opened for signature 23 May 1969, 1155 UNTS 331 (entered into force 27 January 1980) art 31(1). 
[AIDS] was unknown when the Convention came into force, but the Convention is a living instrument which must be interpreted in the light of present-day conditions of living (and - alas! — dying). ${ }^{91}$

The point here, though, is that the correct approach to interpreting the ECHR does not require a great deal of evolution. Isolation and quarantine are clearly within scope. To determine whether lockdown may also come within the scope of the infectious disease exception, we can look to both present-day conditions and the object and purpose of the exception.

The drafters may not have anticipated the use of lockdowns for preventing the spread of infectious diseases. The logistics of such an endeavour may have appeared ludicrous. Present-day conditions, however, render the logistics - if not comfortable - at least achievable. Further, it is only recently that it has become realistic to expect - and, indeed, to witness - a vaccine being developed to counter a novel virus within a year or two. ${ }^{22}$ The purpose of the exception is to prevent the spreading of infectious diseases, which is entirely consistent with the purpose of lockdown. Cumulatively, these factors make it more likely that lockdown will, at least in some circumstances, come within the scope of the exception. If the experiences of the current pandemic result in cases coming before the Court, it may be hoped that this leads to the development of principles better suited to guiding states' public health decision-making so that an appropriate balance can be struck between protecting individual liberty and public health in circumstances of incomplete or changing information.

\section{CONCLUSION}

The European Court of Human Rights has produced the most extensive case law of any human rights jurisdiction in the world, and the inclusion of an express public health exception to the right to liberty suggests that its jurisprudence is likely to provide the best available guidance to states on the circumstances in which physical separation measures against infectious diseases are justifiable and lawful. Despite this, the principles developed to date are limited in their applicability to the current crisis, because they were developed in the context of illnesses that are not directly analogous to the coronavirus driving this pandemic. Many of these limitations are evident in the Victorian curfew case of Loielo, which draws heavily on ECHR case law in determining which rights are engaged. However, that case also essentially breaks new ground in evaluating the necessity

\footnotetext{
Enhorn (n 9) 24 [6].

The first vaccinations against COVID-19 outside of clinical trials were administered in December 2020, with mass vaccination programmes now being rolled-out across the world: 'Covid-19 Vaccine: First person receives Pfizer jab in UK' BBC News (online, 9 December 2020) <https://www.bbc.com/news/uk-55227325>.
} 
and proportionality of a public health measure aimed at large numbers of people, most of whom are unaffected, and which is based predominantly on assessments of various forms of risk.

The drafters of the ECHR may have been surprised by debates over the applicability of art 5(1)(e) to interventions against COVID-19, but it is an evolutive interpretation that demonstrates that even lockdown is likely to be found to fall within the exception. The development in future judgments of principles better suited to large-scale, poorly-characterised diseases is needed to provide adequate guidance to states seeking to implement measures infringe the right to liberty in defence of public health. 